\title{
Atmospheric correction for a Landsat and Sentinel-2 product over water surfaces
}

\author{
$\underline{\text { F. Li }}^{\text {a }}$, D.L.B. Jupp ${ }^{\text {b }}$, S. Sagar ${ }^{\text {a }}$, L.-W. Wang ${ }^{\text {a }}$ and R. Coghlan ${ }^{\text {a }}$ \\ ${ }^{a}$ Environmental Geoscience Division, Geoscience Australia, GPO Box 378, ACT, 2601, Australia \\ ${ }^{b}$ CSIRO, Land and Water, GPO Box 3023, ACT 2601, Australia \\ Email: Fuqin.Li@ga.gov.au
}

\begin{abstract}
In the last decade, satellite derived standard land products have increasingly been produced for medium resolution satellites such as Landsat and (more recently) Sentinel-2. These mostly involve estimating surface reflectance and surface temperature. The products generally remove or standardise atmospheric effects with some normalizing for surface bidirectional reflectance distribution function (BRDF) and terrain illumination effects to provide consistent time series and mosaics. The products have been used in various land surface applications, for instance, land cover, fractional cover, water identification, flooding mapping, crop monitoring and other time series analysis. However, the products are generally not immediately sufficient for applications over persistent water areas, such as estimating water quality, benthic cover, sediment transport, erosion and shallow water bathymetry. These need additional corrections with different physics that are not included in standard land products. In this paper, a method is proposed that treats persistent water areas separately within the standard product and includes corrections not generally applied to the land. The processing has been designed to be fully consistent between water and land in atmospheric correction and to provide comparable definition of reflectance factors so that they can be combined in the same time series and form mosaics. The first step in this process is the use of an effective and up-to-date classification to separate the persistent water and land. The water areas are then atmospherically corrected in the same way as the land without applying BRDF or shading effects. For the water areas, adjacency effects are more significant near the water-land interfaces due to the large contrast between land and water. Water surface effects have also different physics from land surfaces. Therefore, the extra corrections currently include correction for adjacency effects, regional sun glint and sky radiation effects. The water mask and these corrections have been added to the current existing atmospheric, BRDF and terrain corrected surface reflectance product (standard product) from Geoscience Australia (GA). However, at the scale of the Landsat and higher resolution satellite images, residual local surface and bidirectional effects still occur and are discussed in this paper. Results from the new processing strategy have been compared with GA standard products in test images of Canberra and the North Queensland coast near Ingham and used as a basis to discuss the likely residuals of surface and atmospheric effects and options for the inclusion of methods to overcome them in a standard product. The results show that:
\end{abstract}

- $\quad$ Both inland and sea water signatures behave as expected from other data and models.

- Adjacency correction seems most useful where a water-Land interface is close to the water body.

- Sky glint removal is sometimes too much in the Canberra site when water is shielded by local terrain.

- $\quad$ Sun and sky glint correction greatly improves the coast and deep sea water signatures.

Keywords: Adjacency correction, sky and sun glint correction 


\section{INTRODUCTION}

Radiances received by satellites do not directly characterize the underlying reflectance of surface objects and are impacted by atmospheric properties, solar zenith, azimuth, sensor view angles as well as surface slope and surface aspect. To obtain consistent and comparable measures of earth surface from satellite data, methods have been developed to remove these effects and produce a variety of products (Li et al., 2010, 2012) that have proven to be suitable to form time series and mosaics or merged data sets. To date, these products have mostly been used in various land surface applications, e.g., land cover, fractional cover and water identification, flooding mapping, crop monitoring and other time series analysis. However, the products are generally not immediately sufficient for applications over persistent water areas, such as estimating water quality, benthic cover, sediment transport, erosion and shallow water bathymetry. They need some corrections with different physics that are not included in the land standard products.

In response to the need for a standard water product, a water-leaving reflectance time series has been developed within the current GA surface reflectance processing stream. The product is an add-on to the current processing and uses the same code and inputs. The product identifies persistent water areas from land areas using an input water mask developed by GIS and image processing based on the GA water body product (Mueller et al., 2016). In addition to atmospheric correction, the additional processing includes corrections not generally applied to the land, such as an added correction for adjacency effects, regional sun glint and sky radiation effects.

This paper describes the prototype water-leaving reflectance product, its background theory and initial results in the two test areas with different water types, one with inland lakes and the other with coastal and deep sea water.

\section{METHODOLOGY}

\subsection{Adjacency correction}

For water surface, BRDF and terrain shade as applied on the land do not apply. The data are therefore only atmospherically corrected assuming a Lambertian surface. The adjacency correction as well as sun and sky glint corrections for water covered areas has been applied simultaneously with the Lambertian correction based on observed radiance at the top of atmosphere $L_{t o a}$ as follows:

$L_{\text {toa }}=\frac{A \rho_{L}}{1-\rho_{L} S}+L_{a}$

where $\mathrm{L}_{\mathrm{a}}$ is path radiance added by atmosphere, $S$ is atmospheric albedo and $\rho_{\mathrm{L}}$ is the reflectance assuming that the pixel and the surrounding area are uniform and Lambertian so that the reflectance at the surrounding pixels are the same as the target pixel. $A=T_{v}\left(E_{d i r}+E_{d i f}\right) / \pi$, where $E_{d i r}$ and $E_{d i f}$ are the at-surface (Black Earth) direct and diffuse irradiances and $T_{v}$ is total transmittance in view direction.

Equation (1) can be used to derive a Lambertian surface reflectance. However, when the local area is inhomogeneous, the reflectance in the surrounding area can be very different from the target pixel. The Lambertian surface reflectance can then be calculated in a more precise way as (Adler-Golden et al., 2005):

$$
L_{\text {toa }}=\frac{a \rho_{n}+b \rho_{e}}{1-\rho_{e} S}+L_{a}=\frac{A\left[f_{v} \rho_{n}+\left(1-f_{v}\right) \rho_{e}\right]}{1-\rho_{e} S}+L_{a}
$$

where, $a$ and $b$ separate the direct and diffuse components of $A(A=a+b)$ and $f_{v}(=a / A)$ is the direct fraction of radiation in the sensor view direction. The diffuse fraction $\left(1-f_{v}\right)$ can involve influences from adjacent pixels. $\rho_{n}$ is the reflectance of the target pixel and $\rho_{e}$ is the average reflectance in the surrounding pixels. Eq (2) shows that the two ways that the adjacent area is involved are firstly in the top line where it contributes to the diffuse upwelling radiation and secondly in the bottom line where it is involved in the multiple reflections between the atmosphere and the ground. $A, f_{v}, L_{a}$ can be obtained through the radiative transfer model (e.g., MODTRAN) with sufficient atmospheric parameters, e.g., aerosol and water vapour and can be available from current GA processing system except for $\rho_{e}$ which needs a filter to obtain.

In the present system, $\rho_{e}$ is estimated using a filter based on the atmospheric point spread function (Tanré $e t$ al. 1987) and applied to the Lambertian reflectance. Based on this estimate, if the effect of the term $S \rho$ (which is small) is neglected, the target pixel reflectance $\rho_{n}$ can be obtained through Eqs (1) and (2) as: 
$\rho_{n}=\rho_{L}+\left(\frac{\left(1-f_{v}\right)}{f_{v}}\right)\left(\rho_{L}-\rho_{e}\right)$

Written in this form, the change is seen to depend on both the difference in reflectance between a target and its adjacent area and on the amount of diffuse radiation $\left(1-f_{v}\right)$ generated in the view direction. If diffuse radiation is small and/or the adjacent area is similar in reflectance to the target then the change will be small. The correction is therefore most important for high contrasts and in spectral bands with greater amounts of diffuse radiation. Since dark water areas create high contrast with land and the bands most suitable for water analysis (blue to red) have high diffuse radiation when the aerosol load is higher the correction is especially relevant to a water product.

There are two main approaches used to derive the filters and calculate $\rho_{e}$. One is to use the methods based on the work of Tanré, et al. (1987) which used Monte Carlo simulation to generate models of what is called the atmospheric point spread function and develop filters based upon it. The practical applications generally use empirical scaling of filter size based on the band and the excepted aerosol optical depth. The other, more recent, approach is to use a radiative transfer model, such as that was done by Sanders et al. (2001) and Duan et al. (2015). These authors used MODTRAN to compute the point spread function and filter coefficients appropriate for a given waveband and atmospheric parameters. This resolves the need to define atmospheres separately for the computation of the filter and it is possible to use the same atmosphere and atmospheric correction software as is being used for the other terms of the correction. This second method will be used in this paper.

\subsection{Sun and sky glint correction}

Over the sea, there is generally a large area of background environmental effect from the reflections off water at a distance. At times, especially to the east of Australia, this can create broad differences between images that are distinctly visible in mosaics. For this reason, although they are small at the individual pixel scale, corrections for these regional effects have been applied to the product. A regional effect - especially from sky radiation, will also exist for inland waters but it may need some modifications as discussed later.

The local and regional components in the adjusted pixel reflectance $\left(\rho_{n}\right)$ can be written as:

$\rho_{n}=\rho_{w}+\rho_{g}$

The reflectance $\rho_{w}$ is the water leaving reflectance factor which if fully clear of surface effects is equivalent to the factor $R_{r s}$ used by various remote sensing groups (e.g., Pahlevan et al., 2017) since $\rho_{w}=\pi R_{R S}$. A model for the regional surface reflectance term $\rho_{g}$ (incorporating sun and sky effects) can be expressed as (see Guzzi et al., 1987):

$\rho_{g}=f_{s} \rho_{s u u_{-} g}+\left(1-f_{s}\right) \rho_{s k y_{-} g}$

where $f_{s}$ is a direct fraction in the sun direction, $\rho_{s u u_{-} g}$ is the effect of direct sun radiation and $\rho_{s k y_{-} g}$ is a term due to the sky radiation reflecting off the ocean surface over a large area. The first term uses the Cox and Munk (1954) model and the sky reflectance is taken as Fresnel reflectance at the sensor view angle. Based on Cox and Munk (1954), Sturm (1981) and Guzzi et al. (1987), the Fresnel reflectance $\rho_{F}(\theta)$ for a flat ocean at angle $\theta$ is:

$\rho_{F}(\theta)=0.5\left(\frac{\sin ^{2}\left(\theta-\theta^{\prime}\right)}{\sin ^{2}\left(\theta+\theta^{\prime}\right)}+\frac{\tan ^{2}\left(\theta-\theta^{\prime}\right)}{\tan ^{2}\left(\theta+\theta^{\prime}\right)}\right) \quad$ where $\quad \theta^{\prime}=\sin ^{-1}\left(\frac{\sin \theta}{n}\right)$

and $n$ is the refractive index of the water. The refractive index can change with wavelength and environmental conditions (e.g. SST and salinity). The default is taken as 1.34 but can be altered for the processing as appropriate.

The sky term $\left(\rho_{s k y_{-} g}\right)$ is taken to be $\rho_{F}\left(\theta_{v}\right)$, where $\theta_{v}$ is sensor view zenith angle. The sun term is defined as:

$$
\rho_{\text {sun_g }}=\rho_{F}(\omega) g(\omega, \beta, V) \text { with } g(\omega, \beta, V)=p(\beta, V) \frac{\cos \omega}{4 \cos ^{3} \beta}
$$

where $V$ is wind speed. Cox and Munk (1954) assumed a random Gaussian surface in which the probability that sunlight is reflected to angle $\beta$ from the specular direction (for a flat surface) is: 
$p(\beta, V)=\frac{1}{\pi \sigma^{2}} e^{-\frac{\tan ^{2} \beta}{\sigma^{2}}}$ with $\sigma^{2}=0.003+0.00512 V$

The angles $\omega$ and $\beta$ can be calculated as:

$$
\cos \omega=\left[0.5\left(1+\cos \psi_{+}\right)\right]^{0.5} \text { and } \cos \beta=\frac{\cos \theta_{v}+\cos \theta_{s}}{2 \cos \omega}
$$

where $\theta_{s}$ is solar zenith angle and $\psi_{+}$is the phase angle between the view and sun direction and can be defined as:

$$
\cos \psi_{+}=\cos \theta_{s} \cos \theta_{v}+\sin \theta_{s} \sin \theta_{v} \cos \delta \phi
$$

where $\delta \phi$ is relative azimuth angle between sun and view directions. If the surface effects are calculated in this way, the water leaving reflectance $\rho_{\mathrm{w}}$ can be estimated from Eq (4). The wind speed factor above is really a roughness estimate or variance of the wave slope distribution and although attempts have been made to re-calibrate the Cox-Munk model (Bréon and Henriot, 2006) it is still widely used. For the Landsat and Sentinel 2 data sets currently being processed the actual glint hotspot is never imaged and the effect is at most a regional brightening in the sun direction. For higher resolution data sets (including Landsat and similar satellite images) the regional effect does not include all of the surface effects that need to be taken into account for processing water covered areas. The potential to also remove more of the local effects in operational processing will be discussed later. Kay et al. (2009) gave a good review that derives and outlines the current approaches being used to model and adjust for surface effects at different scales.

\section{DATA AND TEST AREAS}

\subsection{Test sites}

Two test sites were used to test the algorithm. One is in Canberra site and the other is along the north Queensland coastal area near Ingham. Canberra is the Australian capital city with a relatively high elevation and is located near the Brindabella Ranges, approximately 150 kilometres inland from Australia's east coast. The urban environs of the city of Canberra surround the Lake Burley Griffin to form a significant contrast for land and water and it is a good area to test algorithms for inland water. The north Queensland coastal area is close to the Lucinda Aeronet site. Approximately one quarter of the image area is located over sea. Both areas have NASA Aeronet sites and have sun photometers to measure aerosol and water vapour data.

\subsection{Data and processing}

Four clear Landsat 8 images and one Sentinel-2a image sensed between 2015 and 2016 were selected to test the algorithm. Table 1 lists the Landsat 8 and Sentinel-2a images used in this study. The images were processed to several levels. For water surfaces, BRDF and terrain illumination correction is not needed, therefore, the water

Table 1. Landsat 8 (L8) and Sentinel-2a (S2) images used in the analysis (UTC is Coordinated Universal Time)

\begin{tabular}{|c|c|c|c|c|c|c|}
\hline \multirow{2}{*}{$\begin{array}{c}\text { Date } \\
(\mathrm{dd} / \mathrm{mm} / \text { year })\end{array}$} & \multirow{2}{*}{ Site } & \multirow{2}{*}{ Satellite } & \multirow{2}{*}{$\begin{array}{l}\text { Path/Row } \\
\text { Or tile }\end{array}$} & \multicolumn{3}{|c|}{ Scene/ tile centre information } \\
\cline { 5 - 7 } & & & & $\begin{array}{c}\text { Time } \\
(\mathrm{UTC})\end{array}$ & $\begin{array}{l}\text { Latitude } \\
\left({ }^{\circ}\right)\end{array}$ & $\begin{array}{c}\text { Longitude } \\
\left({ }^{\circ}\right)\end{array}$ \\
\hline $18 / 06 / 2015$ & Canberra & L8 & $091 / 084$ & 23.93 & $34.61 \mathrm{~S}$ & $148.28 \mathrm{E}$ \\
\hline $16 / 03 / 2016$ & Canberra & L8 & $091 / 084$ & 23.94 & $34.61 \mathrm{~S}$ & $148.30 \mathrm{E}$ \\
\hline $17 / 07 / 2015$ & Lucinda & L8 & $095 / 073$ & 0.27 & $18.79 \mathrm{~S}$ & $146.08 \mathrm{E}$ \\
\hline $26 / 02 / 2016$ & Lucinda & L8 & $095 / 073$ & 0.28 & $18.79 \mathrm{~S}$ & $146.11 \mathrm{E}$ \\
\hline $10 / 02 / 2016$ & Canberra & S2 & HFB & 0.11 & $34.84 \mathrm{~S}$ & $149.91 \mathrm{E}$ \\
\hline
\end{tabular}

processing includes three levels, the ordinary Lambertian process, Lambertian with adjacency correction and finally with sun and sky glint as well. The input data for atmospheric correction, such as aerosol and water vapor are from the local aeronet measurements (https://aeronet.gsfc.nasa.gov/).

\section{RESULTS AND ANALYSIS}

\subsection{Canberra site}

At the Canberra site, two clear Landsat 8 and one Sentinel-2 images were available (see Table 1). The analysis described here is focused on two lakes, Lake Burley Griffin and Lake Ginninderra. Due to the amount and location of sediment flows, the lakes were each separated into two water bodies- one usually with high sediment (named HS) and one usually with low sediment (named LS). An example of the water signatures with high and low sediment is shown in Figure 1 using June 18, 2015 Landsat 8 image. Based on 
previous measurements and literature, the water signature should be different in relation to the amount of sediment, with a sharp peak at about 550nm. The water with wavelength $>900 \mathrm{~nm}$ should be dark but will increase somewhat with sediment and be sensitive to floating materials and other effects. Generally, it is expected that with high sediment, visible region reflectance of the water surface will be high and reduce gradually with increasing wavelength and be close to zero in the shortwave infrared region. With low sediment, surface reflectance over water in these inland lakes is generally expected to be low due to dissolved organic materials (CDOM) and be close to zero when the wavelength $>900 \mathrm{~nm}$. The signature in Figure 1 shows that the two signatures of both lakes are consistent with the literature and adjacency has improved the water signature over the lakes. This effect will likely be greatest near the water edge. Sun and sky glint corrections continue to reduce the reflectance. However, it seems that the total sun and sky glint correction is too much in some cases and can result in negative reflectance values in the blue region (Figure 1a) of the darker area of the Lake. Whether the glint correction is at a correct level (the water is very dark) or too much will be investigated further. It is possible that the sky view factor due to local terrain will play a significant role in the sky glint from inland lakes.
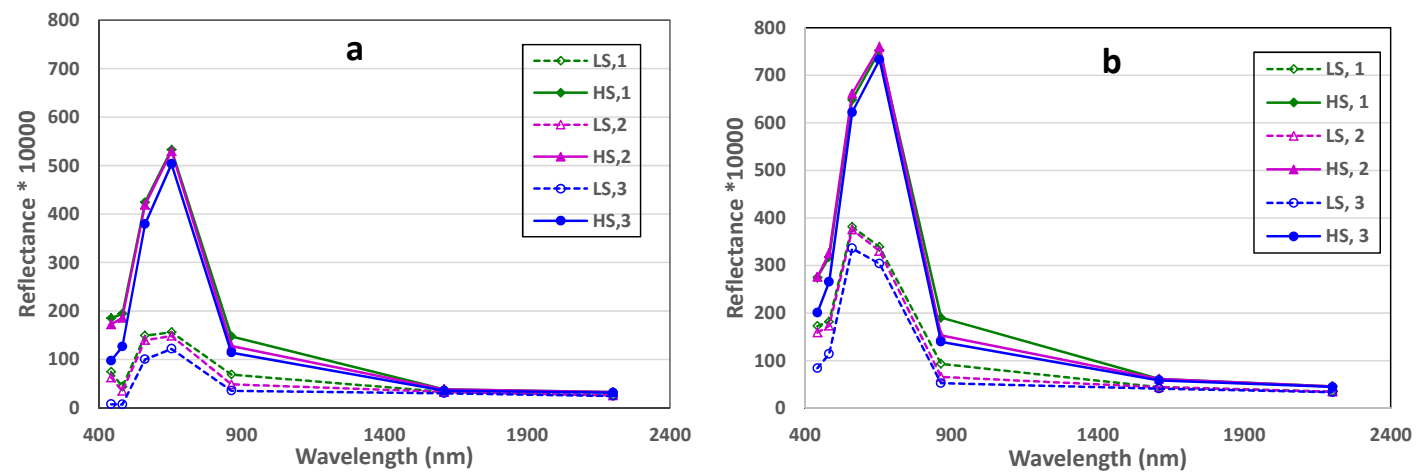

Figure 1. Water signature over (a) Lake Burley Griffin and (b) Lake Ginninderra, where HS and LS are high sediment and low sediment respectively; 1, 2 and 3 represent Lambertian, adjacency corrected and adjacency plus sun and sky glint corrected surface reflectance.

Figure 2 shows the water signatures of Lake Burley Griffin from both Sentinel-2a image (a) and Landsat 8 (b) data. The two images are 35 days apart (Feb 10 and Mar 16 in 2016) and both data sets show that the extra adjacency and glint correction bring the signature to what we might expect, especially the wavelength $>$ $900 \mathrm{~nm}$. In the western basin (LS) the lakes have changed between these dates possibly due to sediment from rain. Independent information is being sought. The extra information near 700nm of Sentinel-2 data can indicate about chlorophyll in the water and will be very useful for water quality monitoring. This is an especially active area for pigments and is away from the dominating sediment peak. Further planned validation studies using site monitoring and measurements will establish how well the data can support models of water quality.
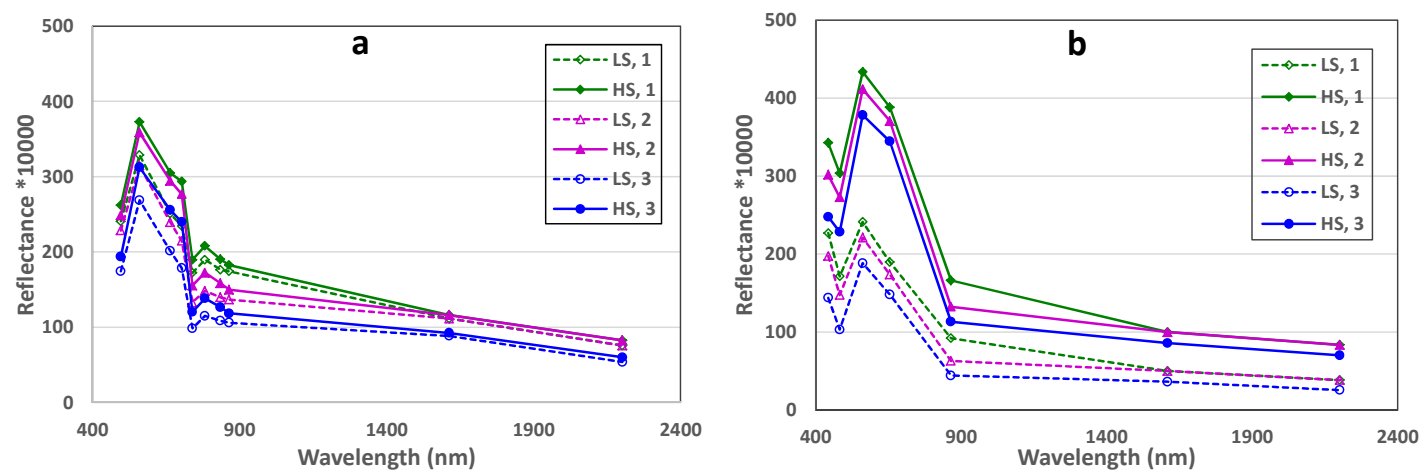

Figure 2. Water signature over Lake Burley Griffin (a) Sentinel-2a sensed on Feb 10, 2016 and (b) Landsat 8 sensed on March 16, 2016, where HS and LS are high sediment and low sediment respectively; 1, 2 and 3 represent Lambertian, adjacency corrected and adjacency plus sun and sky glint corrected surface. 


\subsection{Results at the Lucinda site}

The Lucinda site is different from the Canberra site. Approximately one quarter of the Landsat 8 images are over an ocean surface and it is ideal to test coastal and ocean water effects. According to the distance to the land, the water is classified as two different classes, coastal water $(\mathrm{CW})$ and deep water (DW). Figure 3 shows the signature using three different processing methods for two satellite overpasses.

Since the two classes tested are areas of uniform sea water and do not include the coastline, there is no adjacency effect apparent for both images. However, glint reduction makes the signatures of deep water much more similar, especially for wavelengths $>900 \mathrm{~nm}$. Comparing Figure $3 \mathrm{a}$ with $3 \mathrm{~b}$, it is found that reflectance values at the wavelengths $>900 \mathrm{~nm}$ are very close for the deep water after sun and sky glint correction. The sea water signature becomes similar in two scenes so that it makes the data consistent for time series analysis.
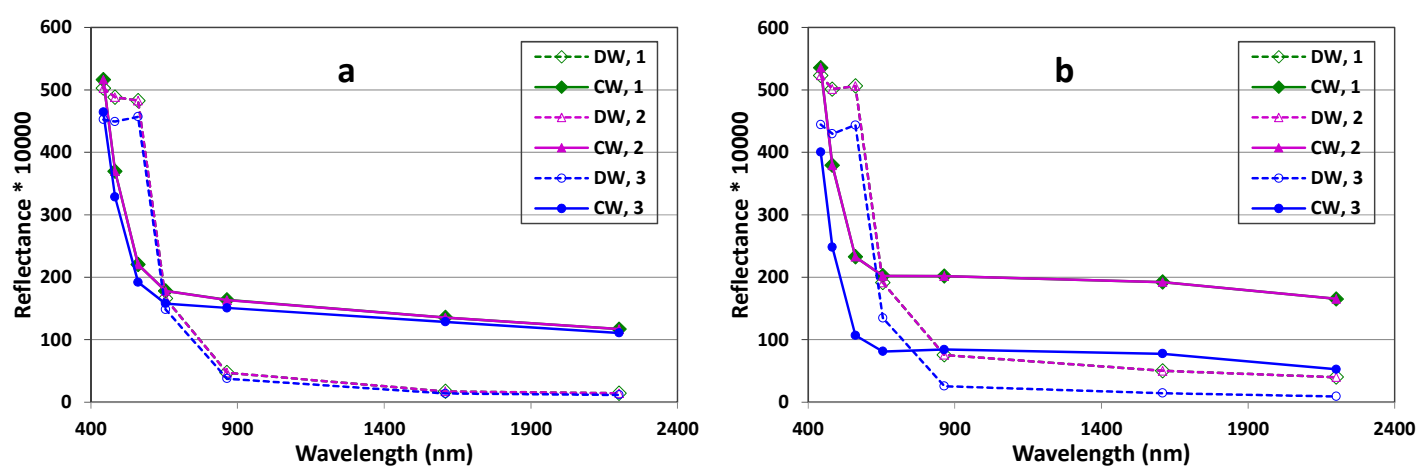

Figure 3. Water signature over North Queensland coast from Landsat 8 (a) sensed on July 17, 2015 and (b) sensed on Feb. 26, 2016, where CW and DW are coastal and deep sea water, respectively; 1, 2 and 3 represent Lambertian, adjacency corrected and adjacency plus sun and sky glint corrected surface.

\section{DISCUSSION}

The regional estimates for surface effects are useful for removing the baseline component but sometimes other local and complex surface effects will remain in the data. Some of these effects have been outlined in Kay et al. (2009). The product described here is designed to be a standard product and these residual effects may be reduced by the time series and data fusion that is part of the product. As the validation experiments occur, there will be discussions as to whether other surface effects may be included to improve the product, such as low frequency swell waves and white caps. Unfortunately, many current local methods still need decisions by experienced scientists and are not suitable for operational processing. Reducing glint effects is the primary step in current water remote sensing. However, water covered areas do have quite strong anisotropic variations in water leaving radiance with sun and view angles and these change with water optical properties so that they have a water BRDF. Previous research in this topic has provided a sound theoretical base as was outlined by Morel et al. (2002). Further research could well bring water and land processing to a full equivalence for time series and mosaics.

\section{CONCLUSIONS}

The initial results show that both inland and sea water signatures behave as expected relative to previous field data and literature. The inland water signatures show very clear spectral responses and are ready for a more detailed validation study based on measurements and models. Adjacency correction seems most useful where a water-land interface is close to the water body. For example, the water signatures in Lake Burley Griffin and Lake Ginninderra have been improved after adjacency correction has been applied. However, sky glint removal may sometimes be too much in the Canberra sites when water is shielded from the sky by local terrain. It is possible that a sky view factor from DEM is needed for the inland water with rough terrain. By contrast, in the coastal and open sea areas away from the coastal strip, the adjacency correction is very small due to uniform surrounding areas. However, sun and sky glint correction greatly improved the coast and water signature. Due to the initial nature of the studies reported here, the variation in contribution due to sun and sky glint has not been fully investigated but in the ocean out to the east of Lucinda the regional sun glint effect is expected to be at its maximum level and the initial tests indicate that the potential to develop 
consistent signatures is very encouraging. The Lucinda site will also be used for a coastal data set in a planned validation study into the accuracy of estimated radiances and reflectance.

\section{ACKNOWLEDGMENTS}

This paper is published with the permission of the CEO, Geoscience Australia (GA) and the permission of CSIRO. Landsat 8 images are provided by GA and Sentinel-2a data are provided by ESA. The water vapour and aerosol data are from NASA Aeronet sites: https://aeronet.gsfc.nasa.gov/. Drs Zhi Huang and Claire Phillips of GA reviewed the early draft of the paper. Anonymous reviewers and editor provided many constructive comments and valuable suggestions that significantly improved the paper.

\section{REFERENCES}

Adler-Golden, S.M., Acharya, P.K., Berk, A., Matthew, M.W. and Gorodetzky, D. (2005). Remote bathymetry of the littoral zone from AVIRIS, LASH and QuickBird imagery. IEEE Transactions on Geoscience and Remote Sensing, 43 (2) 337-347.

Bréon, F. and Henriot, N. (2006). Spaceborne observations of ocean glint reflectance and modeling of wave slope distributions. J. Geophys. Res., 111, C06005, 1-10.

Cox, C. and Munk, W. (1954). Measurement of the roughness of the sea surface from photographs of the sun's glitter. J. Opt. Soc. Am., 44, 838-850.

Duan, S.B., Li, Z.L., Tang, B.H., Tang, R. and Bi, Y. (2015). Atmospheric correction of high spatial resolution satellite images with adjacency effects: applications to EO1 ALI data. International Journal of Remote Sensing, 36 (19-20), 5061-5074.

Guzzi, R., Rizzi, R. and Zibordi, G. (1987). Atmospheric correction of data measured by a flying platform over the sea: elements of a model and its experimental validation. Appl. Opt., 26, 3043-3051.

Kay, S., Hedley, J.D. and Lavender, S. (2009). Sun glint correction of high and low spatial resolution images of aquatic scenes: a review of methods for visible and near-infrared wavelengths. Remote Sensing, 1, 697730; doi:10.3390/rs1040697.

Li, F., Jupp, D.L.B., Reddy, S., Lymburner, L., Mueller, N., Tan, P. and Islam, A. (2010). An Evaluation of the use of Atmospheric and BRDF Correction to Standardize Landsat Data. IEEE Journal of Selected Topics in Applied Earth Observations and Remote Sensing (JSTARS), 3(3):257-270.

Li, F., Jupp, D.L.B., Thankappan, M., Lymburner, L., Mueller, N., Lewis, A. and Held, A. (2012). A physicsbased atmospheric and BRDF correction for Landsat data over mountainous terrain. Remote Sensing of Environment 124 (2012) 756-770.

Morel, A., Antoine, D. and Gentili, B. (2002). Bidirectional reflectance of oceanic waters: accounting for Raman emission and varying particle scattering phase function. Applied Optics, 41 (30), 6289-6306.

Mueller, N., Lewis, A., Roberts, D., Ring, S., Melrose, R., Sixsmith, J., Lymbrner, L., McIntyre, A., Tan, P., Curnow, S. and Ip, A (2016). Water observations from space: Mapping surface water from 25 years of Landsat imagery across Australia. Remote Sensing of Environment, 174, 341-352.

Pahlevan, N., Schott, J.R., Franz, B.A., Zibordi, G., Markham, B., Bailey, S., Schaaf, C.B., Ondrusek, M., Greb, S., Strait, C.M., 2017. Landsat 8 remote sensing reflectance T. Rodrigues et al. / Remote Sensing of Environment 198 (2017) 213-228 227 (Rrs) products: evaluations, intercomparisons, and enhancements. Remote Sens. Environ. 190, 289-301 https://doi.org/10.1016/j.rse.2016.12.030 (ISSN 0034-4257).

Sanders, L.C., Schott, J.R. and Raqueño (2001). A VNIR/SWIR atmospheric correction algorithm for hyperspectral imagery with adjacency effect. Remote Sensing of Environment, 78, 252-263.

Sturm, B. (1981). Ocean colour remote sensing and quantitative retrieval of surface chlorophyll in coastal waters using NIMBUS CZCS data. In Oceanography from Space (J.F. Gower, Ed), Plenum Press (New York, London), p. 267.

Tanré, D., Deschamps, P.Y., Duhaut, P. and Herman, M. (1987). Adjacency effect produced by the atmospheric scattering in Thematic Mapper data. Journal of Geophysical Research, 92 (10), 12,00012,006 . 